\title{
Peripheral Catecholamine Levels and the Symptoms of Anxiety: Studies in Patients With and Without Pheochromocytoma
}

\author{
Monica N. Starkman, MD, MS, Oliver G. Cameron, MD, PhD, \\ RandolPh M. Nesse, MD, and Thomas Zelnik, MD
}

\begin{abstract}
We studied the correlation of plasma and urinary epinephrine (E) and norepinephrine (NE) levels with anxiety symptoms in three patient groups: 1) pheochromocytoma $(\mathrm{PH}+)(n=17)$; 2) hypertensives with elevated catecholamine levels shown not to have a $\mathrm{PH}(\mathrm{PH}-)(\mathrm{n}=25)$; and 3) patients with panic disorder (PD) $(n=23)$. Structured interviews and four self-rated anxiety scales were used. the SCL-90R Anxiety and Phobic Anxiety scales, and the Spielberger State/Trait Anxiety Inventories. The SCL-90R Somatization scale (which measures 12 somatic symptoms) was also utilized. None of the PH+ patients met DSM-III criteria for PD. Two met criteria for generalized anxiety disorder (GAD). Of the PH- patients, two had PD, two had GAD. and three had both. Urinary and plasma $\mathrm{E}$ did not show significant positive correlations with any of the four anxiety scales in any of the three patient groups. In both the PH+ and PH- groups, E was significantly correlated with the SCL-90R Somatization scale. NE was not significantly correlated with any of the four anxiety scales in the PH+ group. In contrast, in the PH- group, plasma NE was significantly correlated with anxiety on all anxiety scales $(r=$ +0.55 to $+0.77, p<0.05$ ). Furthermore, in the $\mathrm{PH}-$ group, plasma NE was significantly correlated with those items of the SCL-90R Anxiety scale measuring the cognitive rather than the noncognitive symptoms of anxiety. In the PD group as well, plasma NE showed a significant correlation with the SCL-90R Anxiety Scale $(r=+0.67, p<0.05)$. Taken together, our observations suggest that: 1) the effects of catecholamines in the periphery derived from a source independent of nervous system control (such as a $\mathrm{PH}$ ) are not sufficient to elicit an anxiety disorder meeting DSM-III criteria; and 2) in patients without an autonomous source of peripheral catecholamines, NE in the periphery results from sympathetic nervous system activation and probably reflects, rather than causes. anxiety.
\end{abstract}

\section{INTRODUCTION}

Recent refinements in the classification of anxiety disorders and the availability of more efficacious pharmacologic treatments have renewed interest in the pathophysiology of anxiety. In this regard,

From the University of Michıgan Medical School, Ann Arbor, Michigan.

Address reprint requests to: Monica N. Starkman, M.D., M.S., Consultation/Liaison Psychiatry, University of Michigan Hospitals, 1500 E. Medical Center Drive. Ann Arbor, MI 48109-0840.

Received May 27, 1988; revision received October 24, 1989 . one area of both historical and current interest is the role played by peripheral as well as central catecholamines.

Three lines of investigation bear on this question. The first addresses catecholamine elevation in response to psychosocial stimuli. Various psychosocial stimuli are known to influence catecholamine levels, but the exact relationship between the kinds of stimuli and the patterns of response remains uncertain. Threat has long been known to induce catecholamine secretion in a variety of species (1). Subsequent research has shown that a wide variety of noxious physical or psychological stimuli release catecholamines $(2,3)$. Pleasant arousal is also associated 
with elevated catecholamine levels (2). More recently, anxiety induced by in vivo flooding in phobic patients was found to stimulate catecholamine excretion independent of pain or muscular activity (4). Some studies of catecholamine secretion suggested that epinephrine (E) release was associated with fear and anxiety and norepinephrine (NE) with aggression (5). Mason (6) proposed that $\mathrm{E}$ was increased in situations characterized by novelty and uncertainty, whereas NE rose in unpleasant but familiar conditions. Levi (7) reported that either positive or negative emotional arousal produces rises in both mean $\mathrm{E}$ and NE levels. In phobic patients undergoing flooding therapy, NE showed a more consistent elevation, whereas $\mathrm{E}$, when elevated, showed a greater magnitude of increase (4). Although patients with panic disorder were thought to show MHPG elevation during situational panic attacks (8), it now appears that panic itself has little effect on plasma MHPG levels (9), and that venous plasma $E$ is unchanged, whereas plasma NE is either unchanged or minimally elevated during spontaneous panic attacks (10). In summary, catecholamines have been shown to change in response to psychological stimuli, but no simple principle explains all of the relationships observed.

The second line of investigation addresses symptoms that result from the administration of catecholamines or "catechol-like" compounds. Isoproterenol induces physical symptoms in normal subjects, including palpitations, dyspnea, and sweating (11). In normal subjects, the emotional reaction to intramuscular injection of $E$ is largely determined by the associated social setting and expectations (12); in a neutral setting, both E and NE have similar effects, neither inducing spe- cific or strong emotions, although their physical effects simulate a state of arousal (2). In patients with panic disorder, isoproterenol may precipitate anxiety attacks (13), even though these patients have $\beta$-adrenergic receptors that are less sensitive than those of normal subjects (14). Thus, catecholamines change psychological states and psychological events change catecholamine levels; the interactions are complex.

The third line of investigation deals with resting levels of catecholamines in psychiatric patients and normal subjects. In some studies, while patients with panic disorder had elevated resting plasma levels of E, NE, and MHPG $(14,15)$, anxiety ratings were not correlated with the catecholamine levels (15). Compared to normal subjects, some panic disorder patients show elevated levels of nighttime urinary $\mathrm{NE}$ and, to a lesser extent, $\mathrm{E}$ (16), and tend to have elevated urinary excretion of MHPG (17). As for patients with generalized anxiety disorder, they may or may not have elevated plasma catecholamine levels (18). In patients with depressive disorder, plasma catecholamine levels correlate better with anxiety ratings than with depression ratings (19), and anxious depressives in particular also have elevated cerebrospinal fluid (CSF) NE levels (20). In normal subjects, one study reported high trait anxiety as measured by the Spielberger Trait Anxiety Scale to be positively correlated with higher plasma MHPG elevations (21), but in another study, plasma MHPG correlated negatively with trait anxiety (22). However, CSF MHPG correlated positively with state anxiety just prior to lumbar puncture (22). All in all, while resting catecholamines appear to be somewhat elevated in patients with panic disorder and 


\section{PERIPHERAL CATECHOLAMINE LEVELS AND ANXIETY}

are possibly elevated in patients with more generalized anxiety, stronger generalizations are not yet warranted.

Thus, despite previous and current research, the question of whether peripheral $\mathrm{E}$ and $\mathrm{NE}$ play an etiologic role in producing anxiety, as suggested by the James-Lang hypothesis, or are simply concomitants of the state of arousal, has still not been satisfactorily answered.

In order to explore further the relationship between peripheral catecholamine levels and anxiety, we studied the correlation of $E$ and $N E$ with anxiety ratings in three patient groups with special features that bear on this question. One group of patients had pheochromocytomas, tumors of adrenal medullary cells that release high levels of catecholamines into the circulation. They do so autonomously and not through autonomic nervous system stimulation, responding instead to such stimuli as change in position. Since peripheral catecholamines do not appear to cross the blood-brain barrier in physiologically significant amounts (23-25), these patients provide an opportunity to study the effect of autonomously secreted elevated peripheral catecholamine levels on symptoms of anxiety. The second group of subjects were patients with hypertension and/or elevated catecholamine levels, who were initially suspected of having a pheochromocytoma but were subsequently shown not to have such a tumor. The elevated peripheral catecholamines in these patients result not from an autonomous tumor but from sympathetic nervous system activity and sympathetic stimulation of the adrenal medulla, presumably under the complex control of the central nervous system. This group was of interest because the high mean catecholamine levels and wide variation of values among individuals in the group can provide information regarding the association of anxiety symptoms and elevated catecholamine levels which result from sympathetic nervous system activity.

We studied one additional group of patients for comparison. This third group consisted of patients meeting DSM-III criteria for panic disorder or for agoraphobia with panic attacks. This group permitted assessment of whether NE and/or E levels are correlated with the somatic and/or cognitive symptoms of anxiety in patients with anxiety disorders who characteristically have mildly rather than markedly elevated catecholamine levels.

We report here that there were no significant correlations of anxiety symptoms with peripheral $\mathrm{NE}$ or $\mathrm{E}$ levels in the patients with pheochromocytoma. In contrast, in the patients without a pheochromocytoma and in the panic disorder patients, anxiety correlated significantly with plasma NE but not with plasma $E$.

\section{METHODS}

Subjects with Actual or Suspected Pheochromocytoma

Subjects were recruited through the University of Michigan Medical Center Nuclear Medicine Unit, an international referral center which provided a unique opportunity to study patients with suspected pheochromocytoma. The presence of pheochromocytoma was determined by scintigraphic imaging after the injection of $\left[{ }^{131} I\right]$ meta-iodobenzyl guanidine $\left(\left[{ }^{131} \mathrm{l}\right] \mathrm{MIBG}\right)$. This compound resembles NE in molecular structure and is thought to enter the adrenergic tissue of pheochromocytomas by the same uptake mechanism (26).

During a 9-month period, all patients referred for an MIBG scan because of suspected pheochromocytoma were evaluated. Seventeen patients were subsequently determined to have a pheochromocytoma. 
This diagnosis was established by: a) plasma and urine catecholamine and urine catecholamine metabolite levels; b) abnormal scintigraphic images with [131]]MIBC, which is highly specific for pheochromocytoma; and c) the histologic appearance of tumor tissue, when available. Fourteen patients were Caucasian, 2 were Afro-American, and 1 was American Indian. Thirteen were male and 4 were female. Their mean age was 42.5 , with a range of 18 to 68 years. Fourteen of these pheochromocytomapositive patients had sustained persistent hypertension, 2 had paroxysmal hypertension, and 1 was normotensive. Eleven of these patients were receiving $\alpha$-adrenergic blocking agents, and 8 were receiving $\beta$-adrenergic blocking agents. While we would have preferred to study patients drug-free, most had significant hypertension, and antihypertensive medication could not be withdrawn solely for purposes of this study. Elevated blood pressure and heart rate in most of these patients, however, indicated continuing effects of the excessive catecholamine levels despite pharmacotherapy. One patient was receiving a benzodiazepine. No patient was receiving antidepressant or antipsychotic medication.

Twenty-five patients who had an MIBG scan were found not to have a pheochromocytoma. Twentythree of these patients were Caucasian, 2 were AfroAmerican. Fifteen were male and 10 were female. Their mean age was 40 , with a range of 21 to 61 years. Twenty of these 25 pheochromocytoma-negative patients had hypertension, 12 persistent and 8 paroxysmal. At evaluation, 6 patients were receiving $\alpha$-adrenergic blocking agents, and 8 were on $\beta$-adrenergic blocking agents. Two of 25 patients were receiving benzodiazepine medication. None was receiving antidepressant medication, and 1 was receiving antipsychotic medication.

\section{Subjects with Panic Disorder}

Twenty-three patients with panic disorder or agoraphobia with panic attacks were studied. These patients had requested treatment at the University of Michigan Anxiety Disorders Program, and were the same individuals reported on in prior publications $(14,27)$. Diagnoses were established according to DSM-III criteria (28) after a clinical examination by a psychiatrist experienced in diagnosing anxiety disorders (O.G.C., R.M.N.). All subjects were Caucasian. Five were male, and 18 were female. Their mean age was 32 , with a range of 18 to 53 . All subjects were physically healthy (except for mitral valve prolapse in 7), were normotensive, and not taking any medication. All but 2 subjects had been medication-free for a month or more. One patient had taken diazepam and trifluoperazine, and another had taken diazepam and naldolol until two weeks before the study. Fourteen of these 23 patients provided both plasma and urine specimens for catecholamine level studies, while the remaining 9 provided urine specimens only.

\section{Normal Subjects}

In order to obtain a comparison group for levels of catecholamine elevation, plasma and urinary $\mathrm{E}$ and NE were studied in a group of nine normal healthy subjects. Seven were male and two female, with a mean age of 26 and a range of 20-34 years.

Informed consent was obtained from each patient and normal subject after the nature of the study was fully explained.

\section{Psychiatric Evaluation and Self-rated Scales}

A full description of the psychiatric evaluation and self-rated scales used has been reported previously (29). Patients being tested for a suspected pheochromocytoma were given a psychiatric evaluation during the 3-day period of their MIBG scan protocol. The interview was designed to collect data that would bear on the diagnoses of panic disorder, generalized anxiety disorder, and major depressive episodes, as defined by the Diagnostic and Statistical Manual of Mental Disorders (Third Edition) (DSMIII) (28).

The psychological and physical symptoms characterizing paroxysmal episodes ("attacks"), as well as chronic symptoms, were assessed for each individual in the suspected pheochromocytoma group. A description of the first episode (prior to the initiation of antihypertensive medication) was obtained, as well as information about any changes in symptom profile over time or after the initiation of medication.

For all three patient groups, each subject completed the Symptom Checklist-90-Revised (SCLGoR), a self-report symptom inventory designed to measure current psychological symptom status rather than personality (30). The SCL-90R includes an Anxiety scale that reflects levels of somatic and

Psychosomatic Medicine 52:129-142 (1990) 


\section{PERIPHERAL CATECHOLAMINE LEVELS AND ANXIETY}

psychic anxiety, a Phobic Anxiety scale that contains items related to agoraphobia, and a Somatization scale that reflects distress arising from perceptions of bodily functions. The Spielberger State/Trait Anxiety Inventory (31) was also administered to each subject being tested for pheochromocytoma.

Psychological test scores and DSM-III diagnoses were established before knowledge of patients' MIBG scan results or catecholamıne levels.

\section{Hormone Measurements}

Patients with suspected pheochromocytoma were tested for plasma $\mathrm{E}$ and NE on the first morning of their evaluation prior to MIBG study. An indwelling catheter was placed in an arm vein, and patients rested supine for $30 \mathrm{~min}$ before a single blood specimen was drawn. Patients also collected a 12-hr overnight urine specimen at home, refrigerated the sample, and brought it with them on the morning that blood was to be drawn. For purposes of this analysis, values of the 12 -hr overnight urine collection were multiplied by 2 to give an estimate of a 24 -hr value. It should be noted that these estimates do not reflect circadian variability (slightly greater excretion during the daytime).

Plasma levels of $\mathrm{E}$ and NE were determined by a radioenzymatic method (32). Urinary concentrations of unconjugated $\mathrm{NE}$ and $\mathrm{E}$ were determined by the method of von Euler and Lishajko (33). For panic disorder patients and normal subjects, blood specimens were also drawn via an indwelling catheter after patients rested supine for 20,30 , and $40 \mathrm{~min}$; a mean value for these three time points was calculated. Urines were collected as two 12-hr specimens, and a mean value for the two specimens was used in the data analysis. Specimens were processed as described previously $(14,27)$.

\section{Statistical Methods}

Histograms revealed that the raw values of hormone levels in plasma and urine were not normally distributed, especially for pheochromocytoma-positive patients. Natural log transformations produced more normal distributions and were therefore used for the analyses. Univariate correlation coefficients were obtained using Pearson's product-moment correlation. All analyses were done withın-group in order to observe the patterns of association of hor- mone levels in each of the three patient groups. Because of the number of correlations studied, we elected to accept only correlation coefficients both statistically significant and of a magnitude of +0.40 or greater. Given the sample size and our interest in patterns of relationships within a group and across groups, rather than the statistical significance of any single correlation per se, we did not adjust the significance level, and accepted a 0.05 level of significance despite the fact that this may yield an overestimate of the number of statistically significant correlations.

\section{RESULTS}

Mean Catecholamine Levels of

Pheochromocytoma-positive,

Pheochromocytoma-negative, and Panic Disorder Patients

The mean catecholamine levels ( \pm SD) in plasma and urine for all groups are shown in Table 1. Mean levels in nine normal subjects are also given for comparison. As can be seen by inspection, compared to normal levels, the mean catecholamine levels were massively elevated in the pheochromocytoma-positive group, substantially elevated in the pheochromocytoma-negative group, and somewhat elevated in the panic disorder group.

\section{DSM-III Diagnoses and Their Association with Catecholamine Levels}

Pheochromocytoma-positive patients. For the 3-week period preceding the evaluation, 12 of the 17 pheochromocytomapositive patients experienced at least one paroxysmal symptom episode. Headache was the most prominent physical symptom during these episodes; sweating, restlessness, nausea, palpitations and tachy- 
M. N. STARKMAN et al.

TABLE 1. Epinephrine and Norepinephrine Levels in Pheochromocytoma-positive, Pheochromocytoma-negative, Panic Disorder Patients and Normal Subjects

\begin{tabular}{lcccc}
\multicolumn{5}{c}{ Pheochromocytoma-negative, Panic Disorder Patients and Normal Subjects } \\
\hline & $\begin{array}{c}\text { Plasma } E \\
(\mathrm{pg} / \mathrm{ml})\end{array}$ & $\begin{array}{c}\text { Urine } \mathrm{E} \\
(\mu \mathrm{g} / 24 \mathrm{hr})\end{array}$ & $\begin{array}{c}\text { Plasma NE } \\
(\mathrm{pg} / \mathrm{ml})\end{array}$ & $\begin{array}{c}\text { Urine NE } \\
(\mu \mathrm{g} / 24 \mathrm{hr})\end{array}$ \\
\hline Pheochromocytoma-positive $(N=17)$ & $950 \pm 2623^{\mathrm{d}}$ & $105 \pm 191$ & $2376 \pm 1778$ & $432 \pm 307$ \\
Pheochromocytoma-negative $(N=25)$ & $105 \pm 288$ & $10 \pm 9$ & $363 \pm 259$ & $47 \pm 29$ \\
Panic disorder $(N=23)$ & $52 \pm 25$ & $13 \pm 4$ & $298 \pm 85$ & $33 \pm 8$ \\
Normal subjects $(N=9)$ & $31 \pm 24$ & $8 \pm 3$ & $222 \pm 38$ & $18 \pm 5$ \\
\hline
\end{tabular}

"Values are means \pm SD.

cardia, shortness of breath, and epigastric distress also were frequent. Because of the type and number of somatic symptoms they described, 9 of the 17 patients met DSM-III criteria for the physical concomitants of panic attack. However, none of the 17 patients met DSM-III criteria for panic disorder. Although some experienced psychological symptoms such as alertness, wariness, and uneasiness, especially during paroxysmal episodes, they denied experiencing the severe apprehension or fear bordering on terror characteristic of patients with panic disorder. They did not seek out others, as patients with anxiety attacks do, but preferred to rest in a quiet room alone until the paroxysmal attack ceased. Although concerned about the potential dangers of hypertension, most patients did not experience the intense fear of sudden death reported by patients with panic disorder. After the first attack and reassurance that their symptoms were not due to a heart attack, they simply waited for subsequent attacks to end. No patient manifested anticipatory anxiety or avoided going to work because of symptoms. No patient developed agoraphobia. (A comprehensive description of physical and mental symptoms in this group of patients, together with an analysis of symptoms that discriminate significantly among patients with pheochromocytoma and patients with either panic or generalized anxiety disorder, is reported elsewhere (29).)

One pheochromocytoma-positive patient was diagnosed as possible panic disorder. Two patients met criteria for generalized anxiety disorder, and two others were diagnosed as "possible generalized anxiety disorder." Of the four patients with definite or possible generalized anxiety disorder, three were also diagnosed as having a major depressive episode; two of these three patients were quite ill with malignant pheochromocytoma and multiorgan involvement.

The five patients who received a diagnosis, definite or possible, of generalized anxiety (four patients) or panic disorder (one patient) had mean plasma $\mathrm{E}$ levels significantly higher than those of the other 12 patients (Kruskal Wallis ANOVA for nonparametric data: $2983 \pm 4493 \mathrm{pg} /$ $\mathrm{ml}$ versus $102 \pm 90 \mathrm{pg} / \mathrm{ml}, p<0.02$ ). There was a trend toward higher mean NE levels in this group as well. Individual values are given elsewhere (29).

Pheochromocytoma-negative patients. In the pheochromocytoma-negative sample of 25 patients, 2 had panic disorder, 2 had generalized anxiety disorder, and 3 received diagnoses of both panic disorder and generalized anxiety (at least one definite). In the pheochromocytoma-negative group, there were no significant differences in mean levels of plasma or urine $\mathrm{E}$ 


\section{PERIPHERAL CATECHOLAMINE LEVELS AND ANXIETY}

or NE between patients with and without a DSM-III anxiety disorder diagnosis.

\section{Correlations of Anxiety Scores and Catecholamine Levels}

Norepinephrine. In the pheochromocytoma-positive group, NE was not significantly correlated with scores on any of the four anxiety scales studied (SCL-90R Anxiety; SCL-90R Phobic Anxiety; Spielberger State; Spielberger Trait).

In contrast, in the pheochromocytomanegative group, plasma NE was significantly correlated with scores on all four anxiety scales. These results are shown in Table 2, upper half. When the 7 pheochromocytoma-negative patients with a DSM-III diagnosis were excluded from the analysis, the correlations between plasma $\mathrm{NE}$ and the anxiety scales for the remaining 18 pheochromocytoma-negative patients remained significant, and became even stronger.

In the panic disorder patients, too, plasma NE showed a significant correlation with scores on the SCL-90R Anxiety scale. As noted previously, the Spielberger Anxiety Scales were not administered to this group. These results are also shown in Table 2.

In order to specify more precisely the nature of the relationship, we further subdivided the 10 items comprising the SCL90R Anxiety scale into three groups: five items that describe cognitive aspects of anxiety, two that are mixed cognitive and somatic, and three that are primarily somatic. These subgroups and the following results are shown in Table 3 . In the pheochromocytoma-positive patients, NE was not significantly correlated with any of the 10 individual items comprising the SCL-90R Anxiety scale. In the pheochromocytoma-negative patients, plasma NE was significantly correlated with four of the five items that are related to the cognitive experience of anxiety. In contrast, plasma NE was significantly correlated with only one of the five noncognitive or mixed items: heart racing or pounding,

TABLE 2. Correlations of SCL-90R and Spielberger Scales with Catecholamines (Pearson's ProductMoment Correlation Coefficients)

\begin{tabular}{|c|c|c|c|c|c|c|}
\hline & \multicolumn{2}{|c|}{$\begin{array}{c}\text { Pheochromocytoma } \\
\text { positive }\end{array}$} & \multicolumn{2}{|c|}{$\begin{array}{c}\text { Pheochromocytoma } \\
\text { negative }\end{array}$} & \multicolumn{2}{|c|}{ Panic disorder } \\
\hline & Plasma & Urine & Plasma & Urine & Plasma & Urine \\
\hline & \multicolumn{6}{|c|}{ Correlation coefficients for NE } \\
\hline SCL-90R Anxiety Scale & NS & NS & $+0.40^{\star}$ & NS & $+0.67^{\star}$ & NS \\
\hline SCL-90R Phobic Anxiety & NS & NS & $+0.55^{*}$ & NS & NS & NS \\
\hline Spielberger State Anxiety & NS & NS & $+0.44^{\star}$ & NS & $N A^{a}$ & NA \\
\hline \multirow[t]{2}{*}{ Spielberger Trait Anxiety } & NS & NS & $+0.49^{\star}$ & NS & NA & NA \\
\hline & \multicolumn{6}{|c|}{ Correlation coefficients for $E$} \\
\hline SCL-90R Anxiety Scale & NS & NS & NS & NS & NS & NS \\
\hline SCL-90R Phobic Anxiety & NS & NS & NS & $-0.57^{\star \star}$ & NS & NS \\
\hline Spielberger State Anxiety & NS & NS & NS & NS & NA & NA \\
\hline Spıelberger Trait Anxiety & NS & NS & NS & NS & $N A$ & NA \\
\hline
\end{tabular}


M. N. STARKMAN et al.

TABLE 3. Correlations of SCL-90R Anxiety Scale Individual Items with Norepinephrine (Pearson's Product-Moment Correlation Coefficients)

\begin{tabular}{|c|c|c|c|c|c|c|}
\hline & \multicolumn{2}{|c|}{$\begin{array}{c}\text { Pheochromocytoma } \\
\text { positive }\end{array}$} & \multicolumn{2}{|c|}{$\begin{array}{c}\text { Pheochromocytoma } \\
\text { negative }\end{array}$} & \multicolumn{2}{|c|}{ Panic disorder } \\
\hline & Plasma & Urine & Plasma & Urıne & Plasma & Urine \\
\hline \multicolumn{7}{|l|}{ Cognitive } \\
\hline Fearful & NS & NS & $+0.55^{\star \star}$ & NS & NS & NS \\
\hline $\begin{array}{l}\text { Suddenly scared for no rea- } \\
\text { son }\end{array}$ & NS & NS & $+0.68 * \star$ & NS & NS & NS \\
\hline Sudden spells terror & NS & NS & $+0.46^{\star}$ & NS & $t$ & NS \\
\hline Somethıng bad will happen & NS & NS & NS & NS & NS & NS \\
\hline Frightening thoughts & NS & NS & $+0.55^{\star \star}$ & NS & $+0.63^{\star}$ & NS \\
\hline \multicolumn{7}{|l|}{ Mixed Cognitive/Somatic } \\
\hline Nervous, shaky & NS & NS & NS & NS & NS & NS \\
\hline Tense, keyed up & NS & NS & NS & NS & NS & \\
\hline \multicolumn{7}{|l|}{ Somatic } \\
\hline Trembling & NS & NS & NS & NS & $+0.56^{\star}$ & NS \\
\hline Restlessness & NS & NS & NS & NS & NS & NS \\
\hline Heart racıng, poundıng & NS & NS & $+0.43^{\star}$ & NS & $+0.68^{\star}$ & NS \\
\hline
\end{tabular}

${ }^{*} p<0.05$.

$\star \star p<0.01$.

† Unable to calculate: all rated maxımum.

which is consistent with its inotropic and chronotropic effects on the heart. Urinary NE showed nonsignificant trends in the same direction for the SCL-90R Anxiety scale and its individual items. For the panic disorder patients there were a few scattered positive correlations of individual items with NE.

Epinephrine. In contrast to NE, E levels were not positively correlated with scores on any of the four Anxiety scales in any of the three groups studied. In fact, urine $\mathrm{E}$ was inversely correlated with the SCL90R Phobic Anxiety scale in the pheochromocytoma-negative group. These results are shown in Table 2, lower half.

When the 10 items of the SCL-90R Anxiety scale were analyzed separately, plasma $\mathrm{E}$ levels in the pheochromocytoma-positive group were significantly correlated with three of the five somatic or mixed cognitive/somatic items (nerv- ous, shaky $r=+0.48, p<0.05$; tense, keyed up $r=+0.57, p<0.05$; trembling $r$ $=+0.56, p<0.05$ ). In the pheochromocytoma-negative group, urinary E showed an inverse correlation with three of the five items related to the cognitive experience of anxiety (fearful $r=-0.40, p<$ 0.05 ; suddenly scared for no reason $r=$ $-0.40, p<0.05$; frightening thoughts $r=$ $-0.51, p<0.05$ ). When the seven pheochromocytoma-negative patients with a DSM-III Anxiety diagnosis were excluded, these inverse correlations between urinary E, the SCL-90R Phobic Anxiety scale and cognitively experienced individual items of the SCL-90R Anxiety scale for the remaining 18 pheochromocytomanegative patients remained significant.

In the panic disorder patients, no significant correlations were found for $\mathrm{E}$ levels and any of the individual items of the SCL-90R Anxiety scale. 


\section{PERIPHERAL CATECHOLAMINE LEVELS AND ANXIETY}

Correlation of Somatic Symptoms and Catecholamine Levels

The SCL-90R Somatization scale includes 12 items related to physical symptoms such as faintness, weakness, nausea, tingling, dyspnea, and hot or cold spells.

Plasma $\mathrm{E}$ in the pheochromocytomapositive group was positively correlated with scores on the somatization scale: $r=$ $+0.51, p<0.05$. Plasma $E$ in the pheochromocytoma-negative group was also positively correlated with scores on the somatization scale: $r=+0.41, p<0.05$. When the 18 pheochromocytoma-negative patients without a DSM-III anxiety diagnosis were analyzed separately, this correlation remained and increased to $r=$ $+0.55 . p<0.05$.

In contrast, $\mathrm{NE}$ in plasma or urine was not significantly correlated with scores on the somatization scale in either the pheochromocytoma-positive or pheochromocytoma-negative patient group.

In the panic disorder patients, neither E nor NE was significantly correlated with scores on the SCL-90R Somatization scale.

\section{DISCUSSION}

Despite major elevations in peripheral catecholamine levels and considerable physical symptoms, the great majority of the pheochromocytoma-positive patients we studied did not meet DSM-III criteria for panic or generalized anxiety disorder. None of 17 such patients we studied described the severe apprehension or fear characteristic of panic attacks. In fact, over $50 \%$ of our sample denied having significant psychologic symptoms of any sort (29). In the pheochromocytoma-positive patient group, there was no significant correlation between anxiety, as measured by four standard scales, and plasma NE or E levels. Somatic symptoms, however, were correlated with plasma $\mathrm{E}$ levels, which is consonant with our knowledge of the peripheral effects of $E$. Since systemic catecholamines do not cross the blood-brain barrier in physiologically significant amounts (23-25), these results suggest that increased peripheral catecholamines secreted by a source autonomous of nervous system control and stimulation are not sufficient to elicit severe anxiety as defined by DSM-III criteria in the majority of patients, even though considerable physical symptoms are experienced.

There are several possible caveats to this conclusion. First, the five pheochromocytoma-positive patients with definite or possible diagnosis of anxiety disorder had plasma E levels significantly higher than those of the other patients. Three of these five patients had malignant pheochromocytoma with metastatic disease, which might account for their anxiety symptoms as well as the additional major depressive disorder diagnosis found in two of the three. Nevertheless, the possibility exists that extremely elevated catecholamine values may play some etiologic role in the production of anxiety. Second, down-regulation of peripheral catecholamine receptors may have occurred over time in patients with pheochromocytomas, perhaps leading to decreased responsiveness to the elevated catecholamine levels. Against this possibility is the fact that the pheochromocytoma-positive patients reported no differences in their current symptoms versus their initial ones. Despite chronic exposure to elevated catecholamines, they reported continuing major episodes of tachycardia, restlessness, shortness of breath, and gastrointestinal symptoms. Third, adrenoreceptor 
blocking agents may have affected the patients' experience of anxiety, even though elevation of blood pressure and heart rate continued despite such medications. Against this possibility is the fact that treating psychiatric patients with generalized anxiety disorder and panic disorder with propranolol, a $\beta$-adrenergic blocking medication which readily enters the brain, has been largely unsuccessful except for decreasing some of the somatic symptoms of anxiety. In our study, pheochromocytoma-positive patients receiving $\beta$-adrenergic blocking medications had no less psychological or somatic symptomatology than the other patients with pheochromocytoma, as shown by Student's $t$ test. The pheochromocytomanegative group provided the opportunity to examine further the possible role of these antihypertensive medications. In this group, Student's $t$ tests revealed no significant differences in plasma and urinary $E$ and NE levels between subgroups of patients receiving and not receiving such medications. Similarly, there were no significant differences in the anxiety scales for patients on, or not on, medication. Medication did not reduce the somatic symptoms experienced by patients; rather, the SCL-90R Somatization scale, which includes headaches, chest pain, and nausea, was higher in patients who were taking medication ( $p<0.03$ ). Lastly, opioid peptides known to be secreted by pheochromocytomas might possibly modulate and have reduced the degree of stimulation of peripheral receptors by catecholamines.

In contrast to the patients with pheochromocytomas, in the pheochromocytoma-negative patients, anxiety ratings were significantly correlated with plasma $\mathrm{NE}$ levels. Again. plasma $\mathrm{E}$ showed no significant correlations with any of the four anxiety scores. Moreover, plasma NE was significantly correlated with individual items of the SCL-90R Anxiety scale related to the cognitive experience of anxiety, but not with items related to the somatic symptoms of anxiety. In individuals without a pheochromocytoma, plasma NE reflects sympathetic nervous system activity; the most direct evidence for this observation is provided by the correlation of plasma NE with levels of sympathetic activity measured electrophysiologically in muscle (34). The patterns of correlations we observed in the pheochromocytoma-negative patients suggests the hypothesis that anxiety originating and experienced cognitively may activate and be linked to the degree of stimulation of the sympathetic nervous system. Thus, NE in the periphery is, at least in part, a marker of this central stimulation. There is some evidence that supports the hypothesis that peripheral NE reflects increased activity of central noradrenergic neurons. In 159 subjects (most of whom had neurologic disease), there was a strong relationship between NE levels in blood and CSF ( $r=+0.78, p<0.001)$, despite the effective blood-CSF barrier for $\mathrm{NE}$ (35). Maas et al. (36) suggest that neuro-anatomic, physiologic, pharmacologic, and biochemical evidence indicate a close coupling of functional activity of the sympathetic nervous system and the catecholamine systems in the central nervous system, so that increased impulse flow in central nervous system catecholamine systems is linked to increased impulse flow in the sympathetic nervous system.

In the pheochromocytoma-negative patients, urinary $\mathrm{E}$ was inversely correlated with the cognitive manifestations of anx- 


\section{PERIPHERAL CATECHOLAMINE LEVELS AND ANXIETY}

iety. The fact that the urinary ratio of NE to $\mathrm{E}$ also showed significant correlations with the SCL-90R Anxiety $(r=+0.50, p$ $<0.05)$ and Phobic Anxiety $(r=+0.70, p$ $<0.01)$ scales further supports the finding. One speculation regarding these results is that psychic anxiety preferentially activates the noradrenergic limb of the sympathetic system, possibly at the "expense" of the epinephrine-secreting adrenal medulla-activatinglimb. In humans, dissociated responses by the sympathetic nervous system and adrenal medullary catecholamine release do occur in response to various stimuli (37). However, further speculation should probably await confirmation of our finding.

Excluding the seven patients with a DSM-III diagnosis from the analysis of the pheochromocytoma-negative group strengthened the correlations between plasma NE, the anxiety scales, and the individual items of the SCL-90R Anxiety scale. This indicates that the correlations for the group as a whole do not result only from the contribution of patients with a clinically diagnosable anxiety disorder. In fact, the opposite was seen: there were no correlations between plasma NE and the anxiety scales in the subgroup with a diagnosable anxiety disorder. On the one hand, this lack of correlation in the anxiety disorder patients may be artifactual. The number of subjects was small, making it difficult to achieve significance. Furthermore, one individual item of the SCL-90R Anxiety subscale: fearfulness, did show a significant correlation with plasma NE ( $r=+0.82, p<0.05)$, and two other cognitive items showed substantial although statistically nonsignificant correlations: suddenly scared $(r=+0.65, p<$ 0.11 ) and sudden spells of terror $(r=$ $+0.58, p<0.17$ ). On the other hand, if the finding is not artifactual, one could speculate that the patients with anxiety disorders differ from the remainder of the pheochromocytoma-negative group in that they manifest a dissociation of the degree of cognitively experienced anxiety and the magnitude of peripheral elevation of NE levels. (For example, these patients might hypersecrete NE so that even low levels of anxiety produce large NE responses. Or, they might have a depleted store of NE due to chronic release, and therefore no ability to respond with greater catecholamine release in the face of greater anxiety.)

The pheochromocytoma-negative patients we studied may represent a population with a specific pattern of catecholamine response to anxiety-provoking stimuli. They were initially sent for evaluation precisely because their paroxysmal or sustained hypertension was associated with elevated catecholamine levels. During our study, plasma catecholamines were obtained preceding an anxiety-provoking situation: a medical investigation. These patients may represent that proportion of the population that responds to certain conditions of stress and anxiety by elevation of NE and responsivity of the vascular system. There is still controversy over whether or not there exists a subgroup of hypertensive patients with elevated basal levels of catecholamines and excessive sympathetic nervous system responsiveness to stress (38, 39). This study would tend to support such a hypothesis.

In summary: 1) None of the patients with pheochromocytoma met DSM-III criteria for panic disorder, while two met criteria for generalized anxiety disorder. Since peripheral catecholamines do not cross the blood-brain barrier, the periph- 
eral effects of $\mathrm{E}$ and $\mathrm{NE}$ secreted by a source autonomous of central nervous system control were not sufficient to elicit anxiety disorders meeting DSM-III criteria in the majority of such patients.

2) E levels were not significantly correlated with any of the four anxiety scales in any of the three patient groups studied. In both the pheochromocytoma-positive and pheochromocytoma-negative patients, E was significantly correlated with the SCL-90R Somatization Scale, which measures 12 physical symptoms.

3) NE levels were not significantly correlated with any of the four anxiety scales in patients with pheochromocytoma. In contrast, in patients without pheochromocytoma and in patients with panic disorder, plasma NE was significantly correlated with the anxiety scales.

4) When the 10 items of the SCL-90R Anxiety scale were categorized according to whether they measured a cognitive or somatic aspect of anxiety, plasma E levels in the pheochromocytoma-positive patients were significantly correlated with three of five somatic or mixed cognitive/ somatic items, but not with any of the five cognitive items. In the pheochromocytoma-positive patients, plasma NE levels were not significantly associated with any individual items. In contrast, plasma NE in pheochromocytoma-negative patients was significantly correlated with four of five items related to the cognitive experience of anxiety, but only one of five noncognitive items.

Taken together, these observations and patterns of correlations support the hypothesis that in individuals without an autonomous source of peripheral catecholamines, NE in the periphery (which is primarily the result of spillover from vascular beds in muscle) results from sympathetic nervous system activity and probably reflects, rather than causes, anxiety.

This work was supported in part by United States Public Health Service grant 5 MO1 RR00042. James C. Sisson, M.D., University of Michigan Division of $\mathrm{Nu}$ clear Medicine, gave encouragement and assistance in facilitating this study.

\section{REFERENCES}

1. Cannon WB: Bodily Changes in Pain, Fear, Hunger and Rage. Appleton, New York, 1915

2. Frankenhauser M: Experimental approach to the study of catecholamines and emotion. In Levi L (ed), Emotions, Their Parameters and Measurement. New York, Raven, 1975, pp 209-234

3. Ward MM, Mefford IN, Parker SD, Chesney MA, Taylor CB, Keegan DL, Barchas JD: Epinephrine and norepinephrine responses in continuously collected plasma to a series of stressors. Psychosom Med 45:471-486, 1983

4. Nesse RM, Curtis GC, Thyer BT, McCann DS, Huber-Smith MJ, Knopf RF: Endocrine and cardiovascular responses during phobic anxiety. Psychosom Med 47:320-332, 1985

5. Silverman A], Cohen SI: Affect and vascular correlates to catecholamines. Psychiatry Res Rep 12:1630, 1960

6. Mason JW: Psychologic stress and endocrine function. In Sachar EJ (ed), Topics in Psychoendocrinology. New York, Grune and Stratton, 1975, pp 1-18

7. Levi $L$ : The urinary output of adrenaline and noradrenaline during pleasant and unpleasant emotional states. Psychosom Med 27:80-85, 1965

8. Ko GN, Elsworth JD, Roth RH, Rifkin BG, Leigh H, Redmond DE: Panic-induced elevation of plasma MHPG levels in phobic anxious patients. Arch Gen Psychiatry 40:425-430. 1983

9. Woods SW, Charney DS, MCPherson CA, Grodman AH, Heninger GR: Situational panic attacks: 


\section{PERIPHERAL CATECHOLAMINE LEVELS AND ANXIETY}

Behavioral, physiologic and biochemical characterization. Arch Gen Psychiatry 44:365-375, 1987

10. Cameron OG, Lee MA, Curtis GC, McCann DS: Endocrine and physiologic changes during "spontaneous" panic attacks. Psychoneuroendocrinology 12:321-331, 1987

11. Weiner N: Norepinephrine, epinephrine and the sympathomimetic amines. In Gilman AG, Goodman LS, Rall TW, Murad F (eds): The Pharmacological Basis of Therapeutics, ed 7. New York, MacMillan Publishing Co, 1985, pp 145-180

12. Schacter S. Singer JE: Cognitive, social and physiological determinants of emotional state. Psychol Rev 68:379-399, 1962

13. Rainey JM Jr, Frohman CE. Freedman RR: Specificity of lactate infusion as a model of anxiety. Psychopharm Bull 20:45-49, 1984

14. Nesse RM, Cameron OG, Curtis GC, McCann DS, Huber-Smith MS: Adrenergic function in panic anxiety patients. Arch Gen Psychiatry 41:771-776, 1984

15. Ballenger JC, Peterson GA, Laraia M, Hacek A, Lake CR, Jimerson D, Cox DJ, Trockman C, Shipe JR, Wilkinson C: A study of plasma catecholamines in agoraphobia and the relationship of serum tricyclic levels to treatment response. In Ballenger JC (ed), Biology of Agoraphobia. American Psychiatric Press, Washington DC. 1983, pp 27-63

16. Nesse RM, Cameron OG, Buda AJ, McCann DS, Curtis GC, Huber-Smith MS: Urinary catecholamines and mitral valve prolapse in panic-anxiety patien s. Psychiatry Res 14:67-74, 1985

17. Sheehan DV, Coleman JH, Greenblatt DJ, Jones KJ, Levine PH, Orsulak PJ, Peterson M, Schildraut JJ, Uzoga ra E, Watkins D: Some biochemical correlates of panic attacks with agoraphobia and their response to a new treatment. J Clin Psychopharmacol 4(2):66-75, 1984

18. Mathew RI. Ho BT, Francis DJ. Taylor DL, Weinman ML: Catecholamines and anxiety. Acta Psychiatr Scand $65: 142-147,1983$

19. Wyatt RJ, Portnoy B, Kupfer DJ. Snyder F, Engelman K: Resting plasma catecholamine levels in patients with depression and anxiety. Arch Gen Psychiatry 24:65-72, 1971

20. Post RM, Lake CR, Jimerson DC, Bunney WE, Wood JH, Ziegler MG, Goodwin FK: Cerebrospinal fluid norepinephrine in affective illness. Am J Psychiatry 135(8):907-912, 1978

21. Uhde TW, Siever LJ, Post RM, Jimerson DC, Boulenger J, Buchsbaum MS: The relationship of plasmafree MHPG to anxiety and psychological pain in normal volunteers. Psychopharm Bull 18(4):129-132, 1982

22. Zuckerman M, Ballenger JC, Post RM: The neurobiology of some dimensions of personality. Int Rev Neurobiol 25:392-436, 1984

23. Oleson J. Hougard K, Hertz M: Isoproteronol and propranolol: ability to cross the blood-brain barrier and effects on cerebral circulation in man. Stroke 9:344-349, 1978

24. Oldendorff WH: Brain uptake of radiolabeled amino acids, amines, and hexoses after arterial injection. Am J Physiol 221:1629-1630, 1971

25. MacKenzie ET, McCullock J, O'Keane M, Pickard JD, Harper AM: Cerebral circulation and norepinephrine: relevance of the blood-brain barrier. Am J Physiol 231:483-488, 1976

26. Sisson JC, Frager MS, Valk TW, Gross MD, Swanson DP, Wieland DM, Tobes MC, Beierwaltes WH, Thompson NW: Scintigraphic localization of pheochromocytoma. N Engl J Med 305:12-17, 1981

27. Nesse RM, Cameron OG, Buda AJ, McCann DS, Curtis GD, Huber-Smith M): Urinary catecholamines and mitral valve prolapse in panic-anxiety patients. Psychiatry Res 14:67-74, 1985

28. Diagnostic and Statistical Manual of Mental Disorders (Third Edition). The American Psychiatric Association, Washington, DC, 1980

29. Starkman MN, Zelnik TC, Nesse RM, Cameron OG: A study of anxiety in patients with pheochromocytoma. Arch Intern Med 145:248-252, 1985

30. Derogatıs LR: SCL-90R Manual I: Scoring and Procedures Manual for the SCL-90R. Clinical Psychometrics Research Unit, Baltımore, 1977

31. Spielberger CD, Gorsuch RL, Lushene RE: STAI Manual for the State-Trait Anxiety Inventory. Consulting Psychologists Press, Inc, Palo Alto, Ca, 1970

32. Peuler JD, Johnson GA: Simultaneous single isotope radioenzymatic assay of plasma norepinephrine, epinephrine and dopamine. Life Sci 21:625-636, 1977

33. von Euler VS. Lishajko F: The estimation of catecholamines in urine. Acta Physiol Scand 45:122-32, 1959 
M. N. STARKMAN et al.

34. Wallin BG: Sympathetic activity in human extremity nerves and its relationship to plasma norepinephrine. In Ziegler MG, Lake CR (eds), Norepinephrine. Williams \& Wilkins, Baltimore, 1984, pp 431-438

35. Ziegler MG, Lake CR, Wood JH, Brooks BR, Ebert MH: Relationship between norepinephrine in blood and cerebrospinal fluid in the presence of a blood-cerebrospinal fluid barrier for norepinephrine. J Neurochem 28:677-679, 1976

36. Maas JW, Koslow SH, Katz MM, Bowden CL, Gibbons RL, Stokes PE, Robins E, Davis JM: Pretreatment neurotransmitter metabolite levels and response to tricyclic antidepressant drugs. Am J Psychiatry 141:1159-1171, 1984

37. Lake CR, Chernow B, Feuerstein G, Goldstein DS, Ziegler MG: The sympathetic nervous system in man: Its evaluation and the measurement of plasma NE. In Ziegler MG, Lake CR (eds), Norepinephrine. Williams \& Wilkins, Baltimore, 1984, pp 1-26

38. Julius $\mathrm{S}$, Ibsen $\mathrm{H}$, Colfer $\mathrm{H}$ : Hemodynamic and pharmacologic correlates of plasma norepinephrine in hypertension. In Ziegler MG, Lake CR (eds), Norepinephrine, Williams \& Wilkıns, Baltimore, 1984, pp $1-26$

39. Goldstein DS, Ziegler MG, Lake CR: Plasma norepinephrine in essential hypertension. In Ziegler MG, Lake CR (eds), Norepinephrine, Williams \& Wilkins, Baltımore, 1984, pp 389-400 